\title{
e-Interview
}

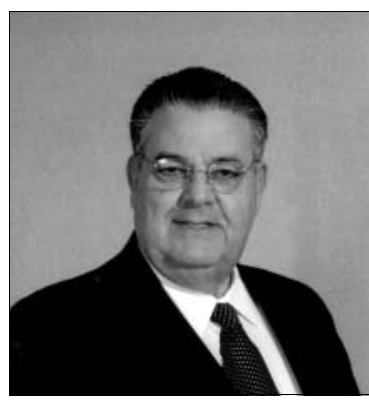

\section{Pedro Ruiz}

Pedro Ruiz is Professor of Psychiatry and Behavioral Sciences at the University of Miami. He studied at the universities of Paris and Miami. His special interests include mood disorders, health services research and cross-cultural psychiatry.

If you were not a psychiatrist, what would you do?

I decided to become a physician at age 10 when my father died from an unknown cause. I almost died at age 12 from peritonitis resulting from a ruptured appendix, which kept me in bed for about 6 months. A few years later, when I was about 15 years old, I read some of Sigmund Freud and Wilhelm Stekel's writings. I decided to become a psychiatrist at this time. If I had not become a psychiatrist, I would certainly have become a primary care physician, which would have allowed me to address personal and family issues from a psychological viewpoint.

What has been the greatest impact of your profession on you personally? Being a psychiatrist has helped me to selfactualise myself through my profession.

Do you feel stigmatised by your profession?

Yes, indeed; unfortunately, a section of our society stigmatises mental illness, and therefore stigmatises mental health professionals also, psychiatrists in particular.

What are your interests outside of work? Reading, travelling and helping people fascinate me.

\section{Why is there so much suffering around} the world?

Poverty leads to misery, discrimination, illnesses and suffering - it must be eliminated.

Who was your most influential trainer, and why?

When I finished my residency training in general psychiatry, I had the unique opportunity to spend, as a faculty member, about 13 years at the Albert Einstein College of Medicine in New York City. In this academic institution, I learnt a great deal, and was exposed to a cadre of faculty who were in my opinion second to none worldwide.

What job gave you the most useful training experience?

I learnt most about psychiatry when I directed a community mental health centre in the South Bronx region of New York City and a 750-bed state psychiatric hospital - the Bronx Psychiatric Center with a large rehabilitation programme and several community-based clinics and programmes.

\section{How has the political environment} influenced your work?

The differing hospital environments in which I have worked throughout my professional career have greatly influenced my way of thinking and my actions. Political factors determine the fate of 'those who have' and 'those who have not'.

\section{What part of your work gives you the} most satisfaction?

Mentoring future leaders in the fields of psychiatry and mental health. I have always enjoyed doing it and, fortunately for me, it has always led to very positive experiences and outcomes.

\section{What do you least enjoy?}

Unfortunately, due to careless political decisions, there have been occasions in which I had to close mental health programmes that I knew were essential for mentally ill individuals in the poorest sectors of society. It really hurt a lot to do that.

What is the most promising opportunity facing the profession?

New scientific discoveries and advances in the biopsychosocial aspects of mental illness, as well as the recent opportunities to positively address stigma and disparities within the health and mental health fields.

\section{What is the greatest threat?}

The lack of courage and sensitivity in government leaders worldwide vis-à-vis global health and mental healthcare needs, especially those populations with no access to healthcare.

What single change would substantially improve quality of care?

Full health and mental healthcare worldwide, and equity of access to care, both to those who have and those who have not.
What conflict of interest do you encounter most often?

Private managed care companies unfairly profiteering in the health and mental health fields.

What is the role of the psychiatrist in countries emerging from conflict?

To provide strong and solid leadership, as well as advocacy and guidance in relation to evidence-based interventions and programme development.

What is the most important advice you could offer to a new trainee? Learn as much as you can, don't compromise the principles that brought you to become a physician, advocate for your patients, and do not ever lose the muchneeded humanistic qualities of the medical profession.

What are the main ethical problems that psychiatrists will face in the future? Attempting to provide full access and high quality of care within a constrained financial environment.

What is the role of the psychiatrist in rebuilding healthcare systems? We must lead, be role models, be advocates for full access to high-quality psychiatric and mental healthcare worldwide.

What single change to mental health legislation would you like to see? Full access to health and mental healthcare for all persons across the world, as well as full parity of medical and psychiatric care.

What single area of psychiatric practice is most in need of development?

Neurosciences, including genetics.

What single area of psychiatric research should be given priority?

Neurosciences, including genetics.

How would you like to be remembered? As a physician/psychiatrist who cared not only for those with illnesses, including mental illness, but also cared for the most disadvantaged and poorest individuals across the world.

Dominic Fannon 